UDK 621.7/.9

DOI: https://doi.org/10.24867/03AM01Tigani

\title{
UPOREDNA TEHNOEKONOMSKA ANALIZA RAZLIČITIH PROCESA SEČENJA ČELIČNOG LIMA
}

\section{COMPARATIVE TECHNOECONOMIC ANALYSIS OF DIFFERENT STEEL PLATE CUTTING PROCESSES}

\author{
Mirsad Tiganj, Fakultet tehničkih nauka, Novi Sad
}

\begin{abstract}
Oblast - MAŠINSTVO
Kratak sadržaj - Osnovni cilj istraživanja orijentisan je na optimizaciju procesa sečenja čeličnog lima sa različitih tehnoloških aspekata. Kao ulazne promenljive definisane su vrsta procesa sečenja, debljina čeličnog lima $i$ brzina sečenja, a kriterijumi tehnoekonomske analize su vreme obrade, dimenziona tačnost, geometrijska tačnost, stepen iskorišćenosti materijala, kvalitet obrađene površine i troškovi obrade, odnosno cena dobijanja gotovih delova sečenjem.

Ključne reči: Sečenje čeličnog lima, tehnoekonomska analiza, gasno sečenje, lasersko sečenje, plazma sečenje

Abstract - The aim of the research is oriented to the optimization of the process of steel plate cutting from different technological aspects. The input variables into the process are the type of a cutting process, the thickness of the steel plates and the cutting speed, whereas the criteria of technoeconomic analysis are processing time, dimensional accuracy, geometric accuracy, material utilization, surface quality and processing cost, that is, the cost obtained from the final part cutting.
\end{abstract}

Key words: steel plate processing, technoeconomic analysis, gas cutting, laser cutting, plasma cutting

\section{UVOD}

Uporedo sa povećanjem zahteva za obradu materijala $u$ metaloprerađivačkoj industriji, razvijaju se nove metode i tehnologije koje su tačnije, produktivnije i ekonomičnije. Danas se za obradu pločastih materijala sečenjem pored konvencionalnih procesa obrade rezanjem sve više upotrebljavaju nekonvencionalni procesi obrade.

Povećanjem preciznosti i tačnosti navedenih obradnih sistema, smanjuje se potreba za višestrukim naknadnim obradama, uz istovremeno postizanje zadovoljavajuće proizvodnosti i ekonomičnosti.

Poznavanjem karakteristika pojedinog procesa obrade, odnosno njihovih mogućnosti i razlika lakše je doneti odluku koji proces u kom slučaju izabrati, odnosno koji je za koje uslove optimalan. Tema ovog rada je orijentisana na upoređivanje tehnoekonomskih karakteristika tri obradna sistema za sečenje materijala koja koriste tri različite tehnologije sečenja laserom, plazmom i gasom $u$ posmatranom proizvodnom sistemu "Metalopromet d.o.o." iz Kule.

\section{NAPOMENA:}

Ovaj rad proistekao je iz master rada čiji mentor je bio dr Dejan Lukić, vanredni profesor.

\section{OSNOVE PROCESA SEČENJA MATERIJALA}

Gasno rezanje/sečenje je postupak razdvajanja metala njegovim sagorevanjem u struji kiseonika, uz istovremeno oduvavanje produkata sagorevanja (troske). Da bi metal sagorevao treba ga zagrejati do temperature paljenja (početka sagorevanja). Gasno rezanje metala spada u termičke postupke, pri čemu se radna temperatura postiže sagorevanjem gorivog gasa (acetilen, propan/butan, zemni gas, ...). Pored toga, sagorevanjem gorivog gasa dobija se deo toplote kojom se radna temperatura održava, a značajan deo toplote dobija se sagorevanjem metala koji se reže. Pravilan proces rezanja se odvija konstantnom brzinom sa neprekidnim mlazom produkata sagorevanja (oksidi u obliku rastopljene troske). Pri tome, plamen koji okružuje mlaz kiseonika, ima zadatak da anulira efekat odvođenja toplote kroz metal van zone rezanja, a mlaz kiseonika mora da sagorevanjem metala obezbedi dovoljno toplote da sagorevanje (rezanje) ostane neprekinuto [1].

Plazma predstavlja četvrto agregatno stanje i suštinski je električno provodljiv, disociran i visokojonizovani gas. U zavarivanju i rezanju se koristi kao relativno tanak mlaz, energije velike gustine (preko 9000A/cm2). Pri sečenju plazmom visoka temperatura mlaza plazme topi $\mathrm{i}$ delimično sublimiše radni predmet, a rastop se oduvava iz reza kinetičkom energijom gasa koji izlazi iz mlaznice, slika 2 [1].

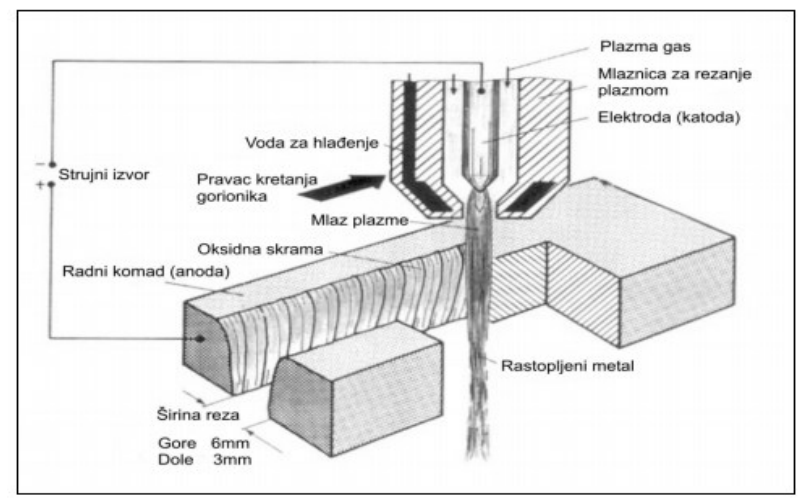

Slika 1. Šematski prikaz gorionika za plazma rezanje [1]

Rezanje plazmom je proces koji se koristi za rezanje čelika i ostalih metala koristeći plazma gorionik. Inertni gas se potiskuje velikom brzinom kroz mlaznicu, dok se $\mathrm{u}$ isto vreme uspostavlja električni luk kroz gas do radnog komada (obratka) pretvarajući jedan deo gasa u plazmu. Plazma je dovoljno topla da proreže materijal i da se otopljeni metal oduva sa reza. 
Reč laser je akronim od "light amplification by stimulated emission of radiation" (pojačanje svetlosti stimulisanom emisijom zračenja). Laserski snop je svetlosni snop. To je u suštini koherentni, konvergentni i mohohromatični snop elektromagnetnog zračenja sa talasnim dužinama od ultraljubičaste do infracrvene [2].
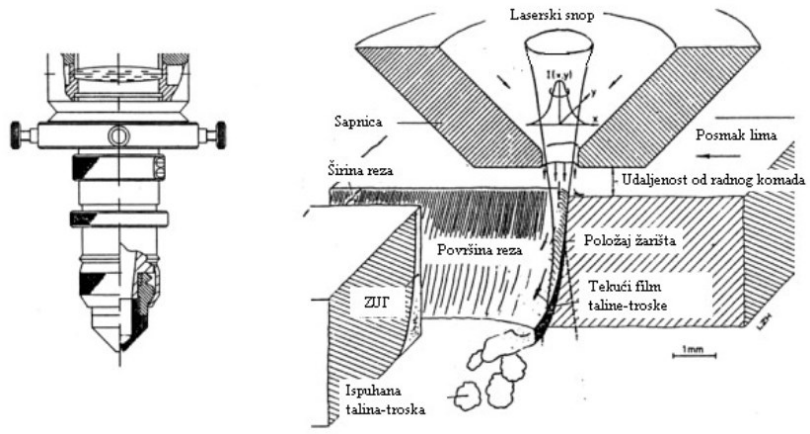

Slika 2. Princip sečenja laserom

Šira primena lasera u industriji počinje u ranim 70-im godinama kada su se pojavili $\mathrm{CO} 2$ i neodijum itrijum aluminijum granat (Nd:YAG) laseri. $\mathrm{CO} 2$ laseri se koriste za sečenje velikom brzinom sa srednjim kvalitetom reza, dok se Nd:YAG laseri koriste za postizanje vrhunskog kvaliteta. Nd:YAG su pogodniji za izradu otvora, uzanih proreza i preciznu obradu, ali njihova cena i troškovi održavanja su mnogo viši u odnosu na CO2 lasere.

Tačnost obrade laserom zavisi od intenziteta i stabilnosti energetskih parametara laserskog zraka i geometrijskih karakteristika optičkog sistema. Zbog konusnog oblika zraka i zbog velikog zagrevanja materijala tokom obrade dolazi do odstupanja dimenzija i oblika. Međutim i pored tih odstupanja, tačnost obrade laserom je vrlo visoka, naročito kod završne obrade $\pm(0,01-0,001) \mathrm{mm}$. Kako bi tačnost obrade bila što je moguće veća, bitno je ostvariti maksimalno fokusiranje laserkog zraka na površini koja se obrađuje. Takođe, tačnost se može povećati ugradnjom dodatnih uređaja, rotacijom laserskog zraka i dr.

\section{EKSPERIMENTALNA ISTRAŽIVANJA}

Planom eksperimenta je predviđeno da se iz čeličnih ploča različite debljine izvrši isecanje određenih delova raspoloživim procesima sečenja, različitim brzinama obrade, kako bi se mogla uraditi uporedna tehnoekonomska analiza [3].

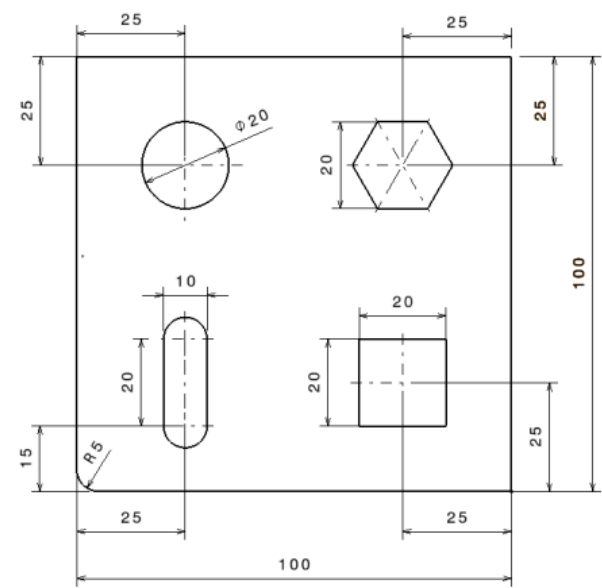

Slika 3. Crtež dela za isecanje
Na bazi ovog plana iz dve ploče različitih debljina - 8 i 15 (mm) izrađenih od ugljeničnog čelika Č.1530 (C45), izvršeno je isecanje delova prema crtežu na slici 3. na mašinama za sečenje laserom, plazmom i gasnim sečenjem za uslove posmatranog proizvodnog sistema.

Za proces sečenja su korišćeni preporučeni ili iskustveni parametri obrade na svakoj od mašina koji su u ovom slučaju varirani sa po dve vrednosti, Vmin i Vmax. U okviru procesa ispitivanja merene su sledeće veličine: vreme obrade, tačnost obrade, kvalitet obrađene površine, stepen iskorišćenja materijala i troškovi obrade.

U tabeli 1, 2 i 3 prikazane su maksimalne i minimalne brzine sečenja $\mathrm{v}[\mathrm{mm} / \mathrm{min}]$ kao i proračunska vremena obrade za debljine materijala $8 \mathrm{~mm}$ i $15 \mathrm{~mm}$.

Tabela 1. Brzina i vreme rezanja laserom

\begin{tabular}{|c|c|c|c|c|}
\hline \multirow{2}{*}{$\begin{array}{c}\text { Debljina } \\
\text { materijala } \\
\mathrm{a}(\mathrm{mm})\end{array}$} & \multicolumn{4}{|c|}{ Lasersko rezanje } \\
\cline { 2 - 5 } & $\begin{array}{c}\text { Max brzina } \\
\mathrm{v}[\mathrm{mm} / \mathrm{min}]\end{array}$ & $\begin{array}{c}\text { Min.brzina } \\
\mathrm{v}[\mathrm{mm} / \mathrm{min}]\end{array}$ & $\begin{array}{c}\operatorname{tr}[\mathrm{s}] \\
\text { pri } \mathrm{v}_{\max }\end{array}$ & $\begin{array}{c}\operatorname{tr}[\mathrm{s}] \\
\text { pri } \mathrm{v}_{\min }\end{array}$ \\
\hline 8 & 700 & 560 & 59 & 73 \\
\hline 15 & 380 & 200 & 108 & 205 \\
\hline
\end{tabular}

Tabela 2. Brzina i vreme rezanja na mašini plazmom

\begin{tabular}{|c|c|c|c|c|}
\hline \multirow{2}{*}{$\begin{array}{c}\text { Debljina } \\
\text { materijala } \\
\mathrm{a}(\mathrm{mm})\end{array}$} & \multicolumn{4}{|c|}{ Plazma rezanje } \\
\cline { 2 - 5 } & $\begin{array}{c}\text { Max brzina } \\
\mathrm{v}[\mathrm{mm} / \mathrm{min}]\end{array}$ & $\begin{array}{c}\text { Min.brzina } \\
\mathrm{v}[\mathrm{mm} / \mathrm{min}]\end{array}$ & $\begin{array}{c}\operatorname{tr}[\mathrm{s}] \\
\operatorname{pri} \mathrm{v}_{\max }\end{array}$ & $\begin{array}{c}\operatorname{tr}[\mathrm{s}] \text { pri } \\
\mathrm{v}_{\min }\end{array}$ \\
\hline 8 & 4350 & 2200 & 9 & 18 \\
\hline 15 & 1650 & 940 & 25 & 44 \\
\hline
\end{tabular}

Tabela 3. Vreme i brzina rezanja pri gasnom sečenju

\begin{tabular}{|c|c|c|c|c|}
\hline $\begin{array}{c}\text { Debljina } \\
\text { materijala } \\
\mathrm{a}(\mathrm{mm})\end{array}$ & \multicolumn{4}{|c|}{ Gasno rezanje } \\
\cline { 2 - 5 } & $\begin{array}{c}\text { Max brzina } \\
\mathrm{v}[\mathrm{mm} / \text { min }]\end{array}$ & $\begin{array}{c}\text { Min.brzina } \\
\mathrm{v}[\mathrm{mm} / \mathrm{min}]\end{array}$ & $\begin{array}{c}\operatorname{tr}[\mathrm{s}] \\
\operatorname{pri} \mathrm{v}_{\max }\end{array}$ & $\begin{array}{c}\operatorname{tr}[\mathrm{s}] \text { pri } \\
\mathrm{v}_{\min }\end{array}$ \\
\hline 8 & 480 & 380 & 85 & 108 \\
\hline 15 & 450 & 350 & 91 & 117 \\
\hline
\end{tabular}

\section{PRIKAZ I ANALIZA REZULTATA MERENJA}

$\mathrm{Na}$ narednim slikama su prikazani isečeni delovi, na svakom od obradnih sistema, za debljinu od $8 \mathrm{~mm}$
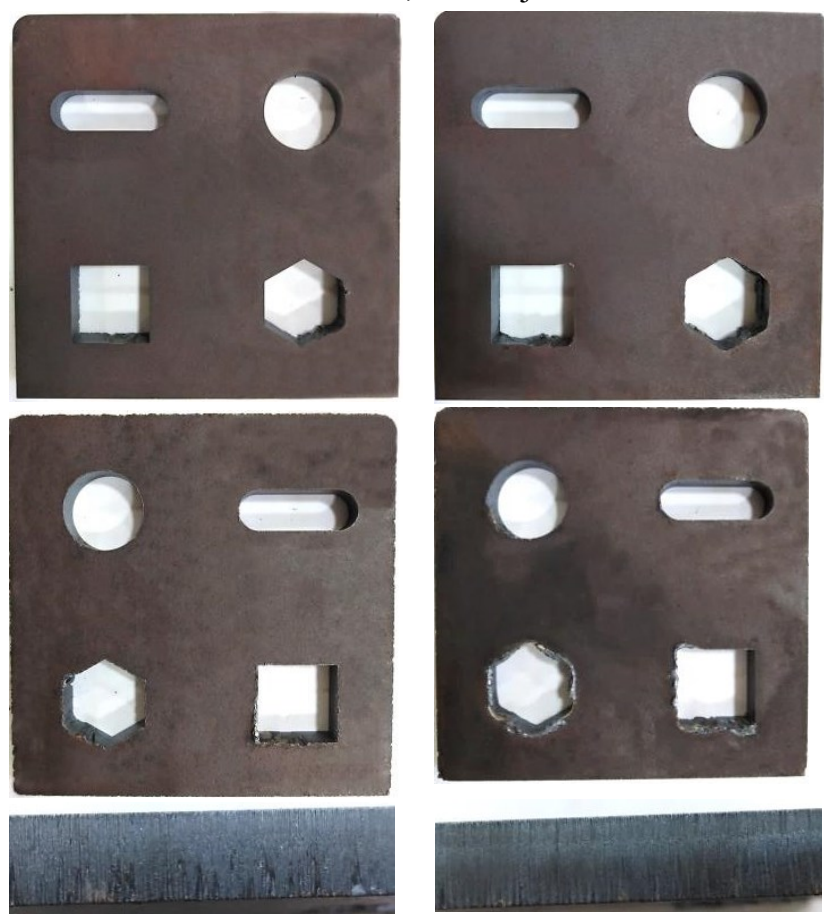

Slika 4. Prednja, zadnja i bočna strana uzorka debljine $8 m m$ sečenog na laseru pri $V_{\max }\left(\right.$ levo) $i V_{\min }$ (desno) 
Na slici 4 se može videti da je opšte stanje obradaka prihvatljivo i da se ovakvi obradci sečeni laserom mogu koristiti uz dodatnu obradu kod manje zahtevnih proizvoda. $\mathrm{Na}$ nekoliko mesta se vide veća brazdanja materijala koja su nastala zbog parametara rezanja (najviše brzine) koji nisu optimalni za ove uslove, već su izabrani na bazi iskustva. Duž ivice reza se može uočiti vrlo mala zona uticaja toplote koja dostiže širinu od 1 do $2 \mathrm{~mm}$. Na bočnim stranama su vidljive brazde i tragovi reza koji su zakošeni u pravcu brzine kretanja laserskog zraka, posebno kod veće debljine materijala i veće brzine.
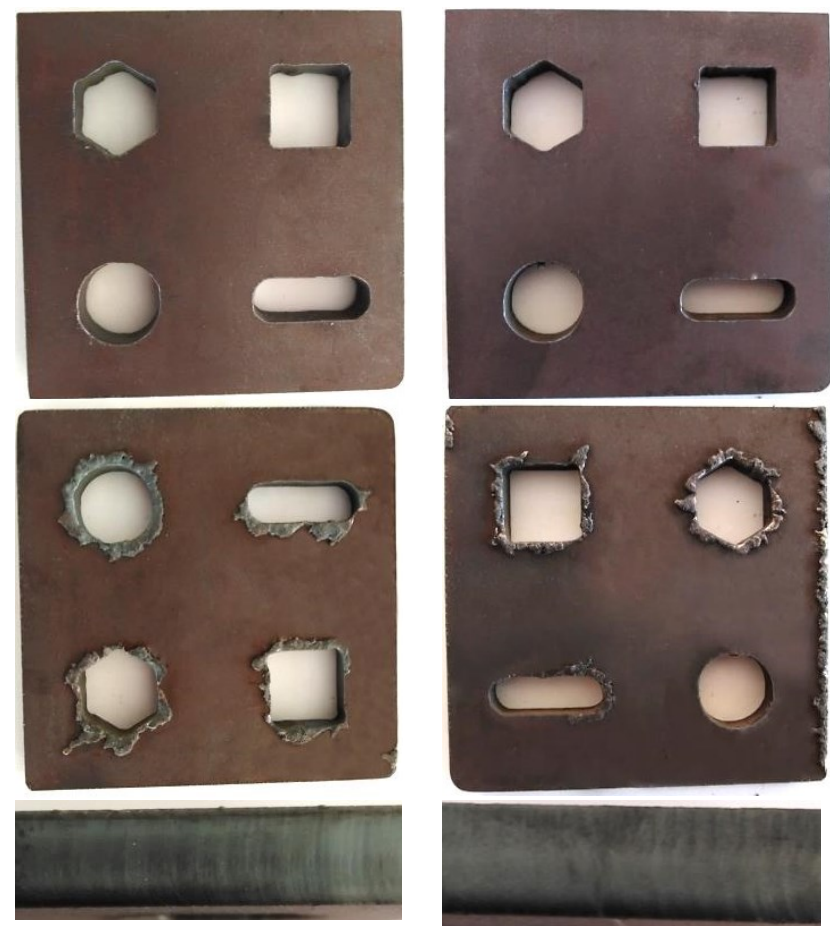

Slika 5. Prednja, zadnja i bočna strana uzorka debljine $8 m m$ sečenog plazmom pri $V_{\max }\left(\right.$ levo) $i V_{\min }$ (desno)
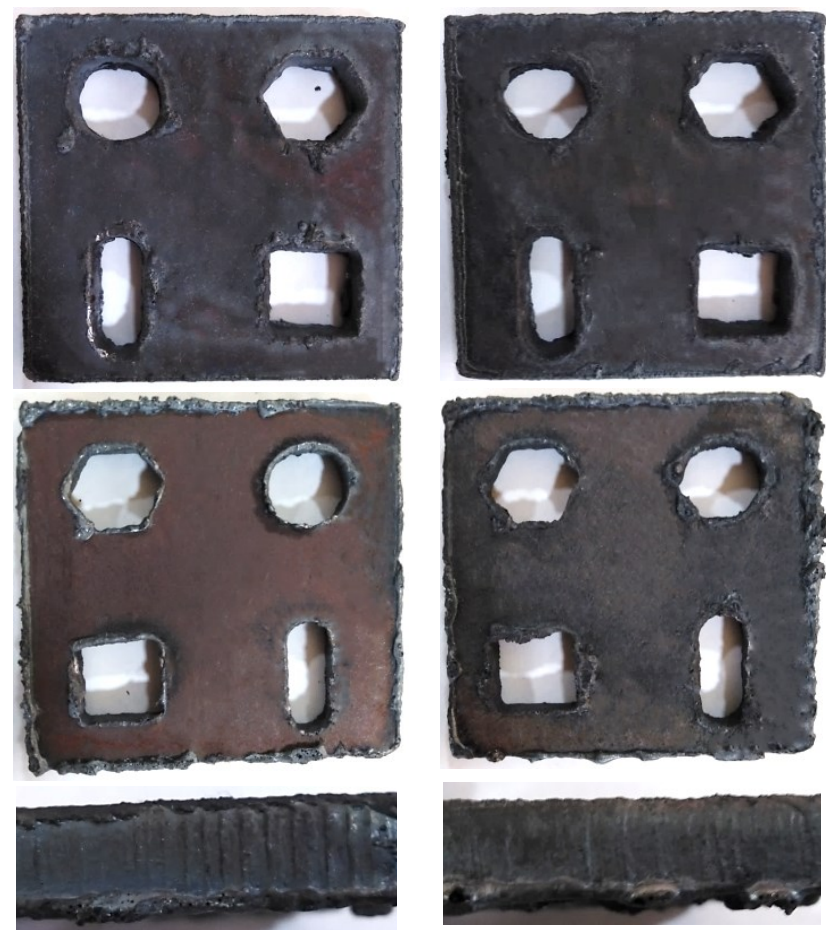

Slika 6. Prednja, zadnja i bočna strana uzorka debljine $8 m m$ sečenog gasom pri $V_{\max }\left(\right.$ levo) $i V_{\min }$ (desno)
Na bazi vizuelnog posmatranja i analize analize obrađenih delova plazmom (slika 5) može se uočiti da je sa prednje strane stanje obradaka prihvatljivo, dok se na zadnjoj strani javlja taloženje rastopljenog materijala, koji se prilično lako odvaja. Vidljiva je zona uticaja toplote koja na nekim mestima dostiže i do $4 \mathrm{~mm}$, a osim toga nema značajnih promena na površini. Bočna strana je sjajna, prihvatljivog kvaliteta sa vidljivim tragovima rezanja $u$ vidu brazdanja materijala. Rez je zakošen, u obliku konusa. Kako bi ovi obradci mogli da se koriste za potrebe montaže ili neke slične namene potrebno je čišćenje zadnje strane i naknadna obrada konusnih površina ukoliko to zahteva konstrukcija proizvoda.

$\mathrm{Na}$ osnovu pregleda obrađenih delova gasnim rezanjem (slika 6) donešeni su sledeći zaključci. Stanje obradaka je prilično lose sa tim da je na prednjoj strani malo bolje nego na zadnjoj strani, gde se javlja taloženje značajne količine materijala u vidu troske. Izrazito je vidljiva zona uticaja toplote koja na nekim mestima dostiže i do $7 \mathrm{~mm}$. $\mathrm{Na}$ bočnoj strani se nalazi rastopljena troska, neprihvatljivog kvaliteta sa vidljivim tragovima rezanja $\mathrm{u}$ vidu brazdanja materijala. Rez je zakošen, u obliku konusa. Obradci sa ovakvim rezom ne bi mogli da se koriste za potrebe montaže ili za ugradnju u neke druge konstrukcije jer ne zadovoljavaju vizuelnu kontrolu tj. potrebno je čišćenje troske $\mathrm{i}$ ponovna obrada dimenzija koje značajno odstupaju, što znači da bi dodaci za obradu bili veliki.

Zbog obima rada prikazaće se samo neki od dobijenih rezultata merenja iz [3].

\section{Tačnost dimenzionih mera}

Za merenje dimenzione tačnosti obrade korišćeno je pomično merilo klase tačnosti $0,05 \mathrm{~mm}$. Na slici $7 \mathrm{su}$ prikazane dimenzije koje su merene. Za svaku dimenziju izvršeno je merenje u nekoliko tačaka i usvojeno je maksimalno odstupanje.

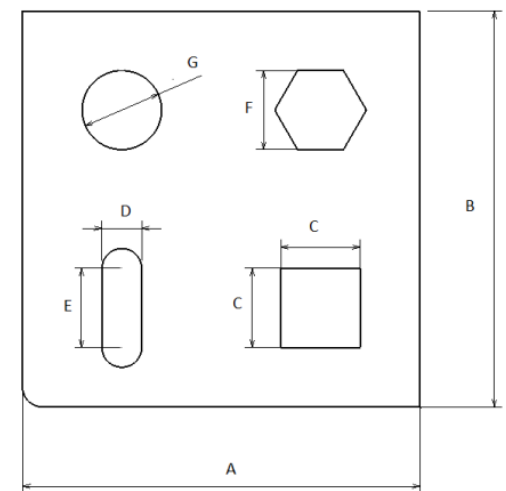

Slika 7. Prikaz dimenzija koje su merene

$\mathrm{Na}$ osnovu 84 rezultata dimenzionih merenja za različite procese obrade, različite debljine i brzine rezanja dobijene su sledeće srednje vrednosti odstupanja od zadate mere:

- Obrada laserom: $0,47 \mathrm{~mm}$

- Obrada plazmom: $0,6 \mathrm{~mm}$

- Obrada gasom: 2,55mm

Dobijeni podaci ispitivanja tačnosti merenih dimenzija pokazuju da je najpreciznija mašina za sečenje laserom, dok iza nje slede plazma i na kraju gasno sečenje kod koga je odstupanje od dimenzija značajno. 


\section{Rezultati merenja ugla nagiba reza}

Ugao nagiba reza, odnosno konus na obrađenim delovima je meren mašinskim na obradcima debljine $8 \mathrm{~mm}$ i $15 \mathrm{~mm}$ za svaki proces sečenja.

$\mathrm{Na}$ delovima sečenim laserom uočen je najmanji konus na obradcima koji iznosi svega $1.5^{\circ} \div 3^{\circ}$, gde je veća mera na gornjoj strani obradka.

$\mathrm{Na}$ obradcima sečenim plazmom izmeren je konus koji iznosi $2^{\circ} \div 4^{\circ}$, na ovim obradcima manja mera je na gornjoj strani obradka, dok je na obradcima sečenim gasom izmeren konus koji iznosi $2^{\circ} \div 4^{\circ}$ kod koga je manja mera na gornjoj strani obradka.

\section{Rezultati merenja ravnosti}

Prilikom sečenja materijala dolazi do znatnog uticaja toplote na radni komad. Uticaj toplote na radni komad uzrokuje deformacije na obradku, odnosno njegovo krivljenje.

$\mathrm{Na}$ osnovu izmerenih vrednosti maksimalnih odstupanja ravnosti može se zaključiti da je odstupanje od ravnosti, odnosno veličina iskrivljenosti delova usled toplote najveća kod gasnog rezanja a potom kod rezanja plazmom, dok je najmanje kod lasera, što se moglo i predpostaviti s obzirom na prirodu procesa sečenja.

\section{Rezultati merenja hrapavosti obrađene površine}

Hrapavost obrađene površine je merena pomoću uređaja MarSurf PS1 na spoljašnjoj površini reza na dužini od $17,5 \mathrm{~mm}$. Na slici 8 prikazani su rezultati merenja hrapavosti obrade plazmom za debljinu $8 \mathrm{~mm}$ pri $\mathrm{v}_{\max }$

$\mathrm{Na}$ osnovu rezultat merenja napravljena je tabela 4 dobijenih stepena hrapavosti $\mathrm{N}$ za posmatrane procese, mašine i sečene debljine materijala

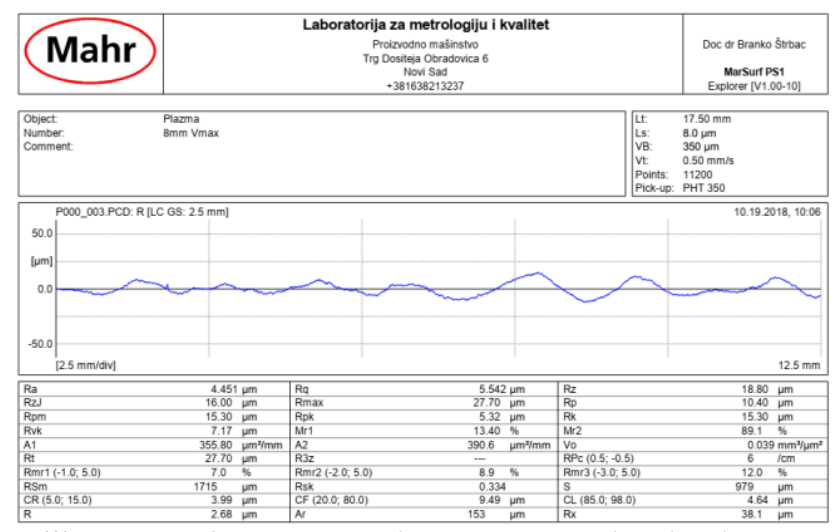

Slika 8. Rezultati merenja hrapavosti za obradu plazmom za debljinu $8 m m$ kada je $V_{\max }$

Tabela 4. Rezultati merenja hrapavosti

\begin{tabular}{|c|c|c|c|c|}
\hline \multirow{2}{*}{$\begin{array}{c}\text { Debljina } \\
\text { materijala } \\
(\mathrm{mm})\end{array}$} & \multicolumn{2}{|c|}{ Lasersko sečenje } & \multicolumn{2}{c|}{ Plazma sečenje } \\
\cline { 2 - 5 } & $\mathrm{V}_{\min }$ & $\mathrm{V}_{\max }$ & $\mathrm{V}_{\min }$ & $\mathrm{V}_{\max }$ \\
\hline 8 & $\mathrm{~N} 9$ - N10 & $\mathrm{N} 10$ & $\mathrm{~N} 7$ - N8 & $\mathrm{N} 8$ - N9 \\
\hline 15 & $\mathrm{~N} 10$ - N11 & $\mathrm{N} 10$ - N11 & $\mathrm{N} 8$ - N9 & $\mathrm{N} 8$ - N9 \\
\hline
\end{tabular}

\section{Rezultati vremena i troškova obrade}

Vreme i troškovi proizvodnje predstavljaju osnovne kriterijume za optimizaciju tehnološkog procesa obrade u okviru proizvodnih procesa [4].

Merenje vremena obrade je izvršeno pomoću štoperice, čiji rezultati su predstavljeni u tabeli 5 .
Tabela 5. Uporedni prikaz vremena sečenja

\begin{tabular}{|c|c|c|c|c|c|c|}
\hline \multirow{2}{a}{} & \multicolumn{2}{|c|}{ Laser } & \multicolumn{2}{c|}{ Plazma } & \multicolumn{2}{c|}{ Gasno sečenje } \\
\cline { 2 - 7 }$(\mathrm{mm})$ & $\mathrm{V}_{\min }$ & $\mathrm{V}_{\max }$ & $\mathrm{V}_{\min }$ & $\mathrm{V}_{\min }$ & $\mathrm{V}_{\max }$ & $\mathrm{V}_{\min }$ \\
\hline $8 \mathrm{~mm}$ & $106 \mathrm{~s}$ & $80 \mathrm{~s}$ & $97 \mathrm{~s}$ & $74 \mathrm{~s}$ & $210 \mathrm{~s}$ & $191 \mathrm{~s}$ \\
\hline $15 \mathrm{~mm}$ & $232 \mathrm{~s}$ & $154 \mathrm{~s}$ & $80 \mathrm{~s}$ & $66 \mathrm{~s}$ & $223 \mathrm{~s}$ & $209 \mathrm{~s}$ \\
\hline
\end{tabular}

$\mathrm{Na}$ osnovu ovih rezultat vidi se da ovo vreme malo odstupa od proračunatih vrednosti, te da je najkraće vreme sečenja plazmom, potom laserom, dok je gasno sečenje očekivano najduže.

$\mathrm{Na}$ osnovu analize troškova obrade, odnosno cene gotovih delova na bazi izvršenog proračuna u radu [3], donesen je zaključak da je za razmatrane delove najekonomičnije rešenje obrade - sečenja plazma postupkom, a u slučaju da se traži veća tačnost obrade onda bi se kao rešenje izabralo sečenje laserom.

\section{ZAKLJUČAK}

U zavisnosti od zahteva koji se postavljaju potrebno je preporučiti odgovarajući postupak rezanja, što je i bio jedan od ciljeva rada. Shodno tome u nastavku su date kratke preporuke na bazi sprovedenih istraživanja. Ako je potrebna velika proizvodnost, zadovoljavajućeg kvaliteta, malo više cene, a pri tome debljina obradaka ne iznosi više od 10-15 mm obrada će se vršiti na laseru. U slučaju da se zahteva dobar kvalitet po prihvatljivoj ceni i da su debljine obradaka veće mora se koristiti plazma, pri čemu treba voditi računa da plazma reže samo metalne delove. Ako se moraju seći jednostavni komadi, debljine preko 50 $\mathrm{mm}$, lošijeg kvaliteta sa niskom cenom, gasno sečenje je najbolji izbor.

U cilju dobijanja detaljnijih podataka o karakteristikama posmatranih obradnih sistema, kao nastavak istraživanja predviđa se optimizacija parametara obrade, ispitivanje procesa obrade za druge vrste materijala, kao i definisanje troškova obrade ovih procesa u zavisnosti od vrste materijala, debljine, parametara obrade i dr.

\section{LITERATURA}

[1] Martinovski V., Antić M.: Noviteti u termičkim postupcima rezanja, Mašinski Fakultet, Beograd, 2011.

[2] Gostimirović, M.: Nekonvencionalni postupci obrade, FTN izdavaštvo, Novi Sad, 2016.

[3] Tiganj, M.: Uporedna tehnoekonomska analiza različitih procesa sečenja čeličnog lima, Master rad, Fakultet tehničkih nauka, Novi Sad, 2018.

[4] Todić, V., Penezić, N., Lukić, D., Milošević, M.: Tehnološka logistika $i$ preduzetništvo, FTN izdavaštvo, Novi Sad, 2011.

\section{Kratka biografija:}

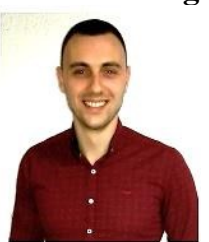

Mirsad Tiganj je rođen u Vrbasu 1991. god. Master rad na Fakultetu tehničkih nauka iz oblasti Mašinstva - Proizvodno mašinstvo / Mehanizacija i konstrukciono mašinstvo, odbranio je 2018. god.

kontakt:mirsad.tiganj991@gmail.com 